\title{
Cost analysis of awake versus asleep deep brain stimulation: a single academic health center experience
}

\author{
R. Lorie Jacob, ScM, ${ }^{1}$ Jonah Geddes, MPH, ${ }^{1}$ Shirley McCartney, PhD, ${ }^{2}$ and Kim J. Burchiel, MD² \\ ${ }^{1}$ Center for Health Systems Effectiveness and ${ }^{2}$ Department of Neurological Surgery, Oregon Health \& Science University, \\ Portland, Oregon
}

OBJECTIVE The objective of this study was to compare the cost of deep brain stimulation (DBS) performed awake versus asleep at a single US academic health center and to compare costs across the University HealthSystem Consortium (UHC) Clinical Database.

METHODS Inpatient and outpatient demographic and hospital financial data for patients receiving a neurostimulator lead implant (from the first quarter of 2009 to the second quarter of 2014) were collected and analyzed. Inpatient charges included those associated with International Classification of Diseases, Ninth Revision (ICD-9) procedure code 0293 (implantation or replacement of intracranial neurostimulator lead). Outpatient charges included all preoperative charges $\leq 30$ days prior to implant and all postoperative charges $\leq 30$ days after implant. The cost of care based on reported charges and a cost-to-charge ratio was estimated. The UHC database was queried (January 2011 to March 2014) with the same ICD-9 code. Procedure cost data across like hospitals (27 UHC hospitals) conducting similar DBS procedures were compared.

RESULTS Two hundred eleven DBS procedures (53 awake and 158 asleep) were performed at a single US academic health center during the study period. The average patient age ( \pm SD) was $65 \pm 9$ years old and $39 \%$ of patients were female. The most common primary diagnosis was Parkinson's disease (61.1\%) followed by essential and other forms of tremor (36\%). Overall average DBS procedure cost was $\$ 39,152 \pm \$ 5340$. Asleep DBS cost $\$ 38,850 \pm \$ 4830$, which was not significantly different than the awake DBS cost of $\$ 40,052 \pm \$ 6604$. The standard deviation for asleep DBS was significantly lower $(p \leq 0.05)$. In 2013 , the median cost for a neurostimulator implant lead was $\$ 34,052$ at UHC-affiliated hospitals that performed at least 5 procedures a year. At Oregon Health \& Science University, the median cost was $\$ 17,150$ and the observed single academic health center cost for a neurostimulator lead implant was less than the expected cost (ratio 0.97).

CONCLUSIONS In this single academic medical center cost analysis, DBS performed asleep was associated with a lower cost variation relative to the awake procedure. Furthermore, costs compared favorably to UHC-affiliated hospitals. While asleep DBS is not yet standard practice, this center exclusively performs asleep DBS at a lower cost than comparable institutions.

http://thejns.org/doi/abs/10.3171/2015.5.JNS15433

KEY WORDS deep brain stimulation; cost; awake; asleep; functional neurosurgery

$\mathrm{D}$ EEP brain stimulation (DBS) has been clearly demonstrated to be more effective than best medical therapy for patients with medically intractable Parkinson's disease. ${ }^{5,19}$ While high-quality clinical outcomes are important, the value of a procedure is also inversely related to cost. Studies of the cost of DBS for Parkinson's disease, and other disease entities, have been performed with increasing frequency over the past decade. ${ }^{1,6-8,13,16} \mathrm{~A}$ number of studies have been published recently that suggest that DBS is cost-effective after the first year or two of therapy, even considering the relatively high cost of the initial implant. ${ }^{2-4,9-12,14,17,20}$

ABBREVIATIONS DBS = deep brain stimulation; ICD-9 = International Classification of Diseases, Ninth Revision; ICU = intensive care unit; IPG = internal pulse generator; LOS = length of stay; OHSU = Oregon Health \& Science University; OR = operating room; UHC = University HealthSystem Consortium.

SUBMITTED February 26, 2015. ACCEPTED May 21, 2015.

INCLUDE WHEN CITING Published online November 20, 2015; DOI: 10.3171/2015.5.JNS15433. 
In our center, we have recently adopted a new method of implanting DBS electrodes, portable CT (CereTom). We were interested in how this new methodology would affect the cost of DBS electrode implantation, and the utilization of operating room (OR) resources. In this study, we compared the historical costs of electrode implantation at our institution in patients under local anesthesia, utilizing microelectrode recording to locate targets ("Awake DBS"), to a newer method in which DBS electrodes were implanted under general anesthesia, using only image guidance ("Asleep DBS"). This cost analysis was then benchmarked to the University HealthSystem Consortium (UHC) database for 26 "high-volume" UHC Clinical Database principle member hospitals for DBS electrode and internal pulse generator (IPG) implantation procedures.

\section{Methods}

At Oregon Health \& Science University (OHSU), preoperative MRI is performed just prior to inpatient hospitalization. DBS electrodes are implanted during an initial overnight hospital stay (Phase 1), and IPGs are implanted from 4 to 9 days later in an ambulatory surgery center (Phase 2). Inpatient care, coded by International Classification of Diseases, Ninth Revision (ICD-9) procedure code 0293, includes implantation of an intracranial neurostimulator lead. Outpatient care consists of the preoperative imaging and eventual implantation of an IPG. In an effort to capture all costs associated with DBS, all outpatient and inpatient charge data from patients receiving a DBS implant at a single academic health center (OHSU) were collected. Included outpatient charges were any preoperative charges recorded within 30 days prior to the implant and any postoperative charges recorded up to 30 days after the implant. Charges that were unrelated to DBS were excluded, such as charges for emergency department visits. Inpatient charges that were included were those associated with the ICD-9 code 0293 intracranial implant encounter.

Costs were calculated using a cost-to-charge ratio, which was calculated from the ratio of total direct cost to total charge by item type. The cost-to-charge ratio was then applied to each line-item charge to approximate costs for the respective fiscal year. Cost-to-charge ratios from fiscal year 2013 were applied to charges of fiscal year 2014.

Asleep DBS was compared with awake DBS (performed before year 2011). Top cost contributors by revenue category for each method and total cost, length of stay (LOS), and readmissions were compared. Surgical procedures were performed by 1 surgeon (K.J.B.); therefore, provider comparisons are not included.

For benchmarking purposes, OHSU's implantation of intracranial neurostimulator leads were compared with 26 "high-volume" UHC Clinical Database principle member hospitals. Benchmarking analysis was limited to the inpatient procedure associated with DBS: ICD-9 procedure code 0293, "implantation or replacement of intracranial neurostimulator lead." High volume was defined as greater than or equal to 5 procedures per year. Direct cost indices, total cost, volume, and average total cost per discharge between OHSU and UHC institutions were compared. UHC benchmarking data, mean total cost, mean observed di-

TABLE 1. OHSU DBS patient demographics (July 2009-March 2014)

\begin{tabular}{|c|c|c|c|}
\hline Patient Characteristics & Awake DBS & Asleep DBS & Total \\
\hline No. of patients (\%) & $53(25)$ & $158(75)$ & $211(100)$ \\
\hline Mean age in yrs (range) & $66(50-82)$ & $64(27-82)$ & $65(27-82)$ \\
\hline Female $(\%)$ & 30 & 42 & 39 \\
\hline \multicolumn{4}{|l|}{ 3M Severity of IIIness (\%) } \\
\hline Minor & 75 & 81 & 80 \\
\hline Moderate & 25 & 18 & 20 \\
\hline Major & 0 & 1 & 0 \\
\hline \multicolumn{4}{|l|}{ Patient status (\%) } \\
\hline Home or self-care & 98.1 & 96.8 & 97.2 \\
\hline Transferred to home health & 1.9 & 0 & 0.5 \\
\hline Transferred to skilled nursing facility & 0 & 2.5 & 1.9 \\
\hline Transferred to a Medicare-certified long-term care hospital & 0 & 0.6 & 0.5 \\
\hline \multicolumn{4}{|l|}{ Primary diagnosis $(\%)$} \\
\hline Parkinson's disease & 71.7 & 57.6 & 61.1 \\
\hline Essential and other specified forms of tremor & 28.3 & 38.6 & 36 \\
\hline Abnormal involuntary movements & 0 & 1.3 & 0.9 \\
\hline Other* & 0 & 2.5 & 2 \\
\hline \multicolumn{4}{|l|}{ Insurance status (\%) } \\
\hline Medicare & 69.8 & 67.7 & 68.2 \\
\hline Contracts (private insurance) & 30.2 & 31.6 & 31.3 \\
\hline Medicaid-Oregon & 0 & 0.6 & 0.5 \\
\hline
\end{tabular}

* Includes headache, other acquired torsion dystonia, temporal sclerosis, and unspecified drug or medicinal substance causing adverse effect in therapeutic use. 
TABLE 2. OHSU DBS cost by all revenue categories (July 2009-March 2014)

\begin{tabular}{|c|c|c|c|}
\hline Revenue Category & Mean Cost \pm SD per Patient (\$) & $\%$ Utilization* & Mean Cost \pm SD per Utilizer (\$)† \\
\hline Medical/surgical supplies & $24,011 \pm 3492$ & 100 & $24,136 \pm 3087$ \\
\hline OR services & $7307 \pm 1563$ & 100 & $7307 \pm 1563$ \\
\hline ICU & $2562 \pm 1319$ & 84 & $3037 \pm 784$ \\
\hline Recovery room & $1594 \pm 645$ & 100 & $1602 \pm 637$ \\
\hline Anesthesia & $631 \pm 185$ & 100 & $631 \pm 185$ \\
\hline Drugs requiring specific identification & $544 \pm 287$ & 100 & $510 \pm 285$ \\
\hline Room \& board (semiprivate, 2 beds) & $415 \pm 1595$ & 13 & $3245 \pm 3317$ \\
\hline MRI & $380 \pm 226$ & 95 & $401 \pm 213$ \\
\hline Coronary care & $379 \pm 979$ & 13 & $2854 \pm 359$ \\
\hline Pharmacy & $278 \pm 126$ & 100 & $302 \pm 142$ \\
\hline CT & $197 \pm 133$ & 78 & $252 \pm 93$ \\
\hline Laboratory & $192 \pm 255$ & 100 & $192 \pm 255$ \\
\hline Physical therapy & $131 \pm 94$ & 91 & $166 \pm 129$ \\
\hline Radiology_diagnostic & $129 \pm 338$ & 30 & $433 \pm 504$ \\
\hline Professional fees & $92 \pm 94$ & 85 & $108 \pm 94$ \\
\hline Clinic & $72 \pm 70$ & 88 & $82 \pm 68$ \\
\hline Occupational therapy & $69 \pm 119$ & 28 & $173 \pm 97$ \\
\hline Electroencephalogram & $28 \pm 295$ & 1 & $1953 \pm 1870$ \\
\hline Electrocardiogram & $27 \pm 17$ & 82 & $33 \pm 13$ \\
\hline Respiratory services & $21 \pm 121$ & 12 & $172 \pm 311$ \\
\hline Treatment or observation room & $21 \pm 177$ & 2 & $1089 \pm 808$ \\
\hline Emergency room & $16 \pm 104$ & 3 & $485 \pm 331$ \\
\hline Cardiology & $14 \pm 60$ & 6 & $235 \pm 80$ \\
\hline Pulmonary function & $14 \pm 9$ & 81 & $17 \pm 7$ \\
\hline Speech-language pathology & $14 \pm 117$ & 3 & $437 \pm 512$ \\
\hline Other diagnostic services & $9 \pm 44$ & 32 & $29 \pm 75$ \\
\hline Other imaging services & $2 \pm 21$ & 1 & $213 \pm 7$ \\
\hline Other therapeutic services & $1 \pm 9$ & 0 & 137 \\
\hline Laboratory pathological & $0 \pm 3$ & 1 & $33 \pm 14$ \\
\hline Psychiatric/psychological services & $0 \pm 3$ & 2 & $17 \pm 11$ \\
\hline Psychiatric/psychological treatments & $0 \pm 1$ & 2 & $7 \pm 5$ \\
\hline Total & $39,152 \pm 5340$ & & \\
\hline
\end{tabular}

* Percentage of patients with costs in the revenue category.

$\dagger$ Mean cost per patient among the patients utilizing the revenue category.

TABLE 3. OHSU DBS outcomes (July 2009-March 2014)

\begin{tabular}{lccc}
\hline \multicolumn{1}{c}{ Outcome } & Awake + Asleep DBS & Awake DBS & Asleep DBS \\
\hline No. of patients (\%) & 211 & $53(25)$ & $158(75)$ \\
\hline Mean cost \pm SD (\$) & $39,152 \pm 5340$ & $40,052 \pm 6604^{*}$ & $38,850 \pm 4830^{*}$ \\
\hline Mean LOS in days \pm SD & $1.18 \pm 0.76$ & $1.23 \pm 0.87$ & $1.16 \pm 0.72$ \\
\hline No. of readmissions (\%) & $9(4.3)$ & $2(3.8)$ & $7(4.4)$ \\
\hline Mean ICU LOS in days \pm SD & $0.9 \pm 0.5$ & $1 \pm 0.5$ & $0.9 \pm 0.5$ \\
\hline Mean OR time in minutes \pm SD & $285.85 \pm 57.83$ & $282.55 \pm 58.55$ & $286.97 \pm 57.72$ \\
\hline In-hospital deaths (\%) & 0 & 0 & 0 \\
\hline 30-day postoperative deaths (\%) & 0 & 0 & 0 \\
\hline 30-day postdischarge deaths (\%) & 0 & 0 & 0 \\
\hline
\end{tabular}

\footnotetext{
* Significant difference between DBS procedures at $p=0.05$ when adjusted by 3M Severity of Illness. Two-sample variance comparison test, $p$
} $=0.0034$. 


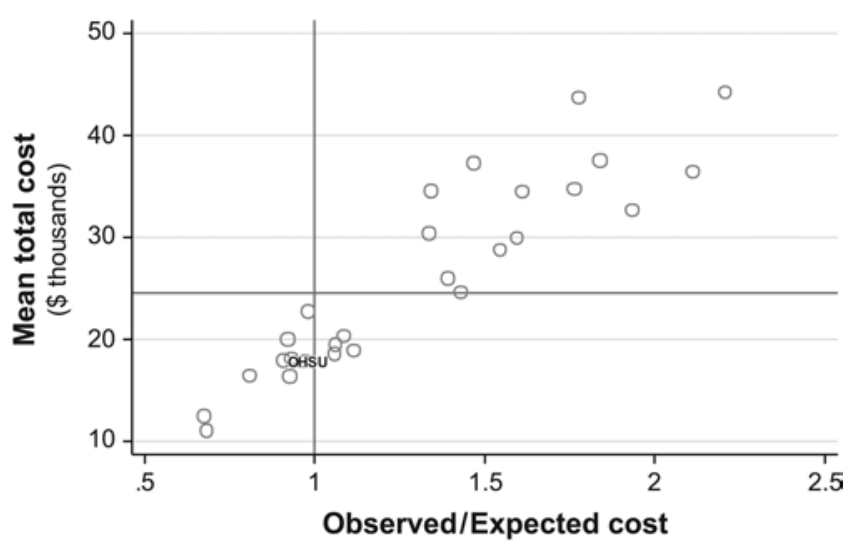

FIG. 1. Scatterplot of cost benchmarking of the ICD-9 code 0293 (neurostimulator implant lead) and adult inpatient cost data from $27 \mathrm{UHC}$ hospitals from January 2011 to March 2014. Data source: UHC.

rect cost, mean expected direct cost, and direct cost index were queried from January 2011 to March 2014. Queries of mean total cost and direct cost index were compared. In these queries, total cost was defined as the sum of direct and indirect costs. Direct costs are costs specifically associated with providing the service or procedure of interest. Indirect costs are those that are related to support services necessary to the procedures and services specified, but not directly related to delivering care. The direct cost index is the observed direct cost over the expected direct cost. Expected direct costs were generated using the UHC 2013 risk adjustment model. Total DBS cost over time was compared with the upper control limit and lower control limit determined by data from the period prior to January 5, 2011, when OHSU still performed awake DBS procedures.

\section{Results \\ Demographics}

Two hundred eleven DBS cases were included in the study period of July 2009 to March 2014. The average patient age was $65 \pm 9$ years and $39 \%$ were women. Overall primary patient diagnosis was Parkinson's disease $(61.1 \%)$ and "essential and other specified forms of tremor" $(36 \%)$. The majority of patients $(80 \%)$ had minor 3M Severity of Illness, and $97.2 \%$ were ultimately discharged home or to self-care; $68.2 \%$ of patients were covered by Medicare and $31.3 \%$ had private insurance coverage (Table 1).

\section{Inpatient and Outpatient Costs Associated With DBS}

All revenue categories were sorted by average per patient cost and the percentage of patients who were billed for the revenue category (\% utilization). For revenue categories, the amount of variance and mean cost per patient were as expected based on OHSU clinical practice. However, more utilization was expected in certain categories, such as CT. Expected CT utilization was $100 \%$, but actual utilization was 78\% (Table 2). Overall, mean DBS cost for both awake and asleep approaches was $\$ 39,152 \pm \$ 5340$. Mean LOS was 1.18 days and readmission rate was $4.3 \%$. The mean OR time was $285.85 \pm 57.83$ minutes. There were no deaths (Table 3).

\section{Awake Versus Asleep DBS}

There were no significant differences in readmissions, LOS, intensive care unit (ICU) LOS, OR time, and cost. Costs included ICD-9 inpatient procedure code 0293 and outpatient costs closely associated with DBS, such as implantation of an IPG (Table 3). The mean cost of asleep DBS $(\$ 38,850 \pm \$ 4830)$ was lower than that of awake DBS (\$40,052 $\pm \$ 6604)$, which was not significant. However, there was a significant difference in the standard deviation $(\mathrm{p}=0.0034)$.

\section{Benchmarking DBS: ICD-9 Procedure Code 0293}

OHSU's observed cost for implanting a neurostimulator lead was less than the expected cost (ratio 0.97; Fig. 1). In 2013, the average cost of implanting neurostimulator leads at OHSU was $\$ 17,150$, less than the group median of $\$ 34,052$ (Table 4). OHSU's cost for these procedures also appeared to be lower than the median among institutions that performed at least 5 of these procedures a year (Fig. 2, Table 4).

Total DBS costs over time were compared, as indicated in Fig. 3 by the awake DBS mean (Fig. 3, grey line) and asleep DBS mean (Fig. 3, black line). One observation $(1.85 \%)$ is above the upper control limit in the awake period. Three observations $(1.88 \%)$ exceed 3 times the standard deviation in the asleep period. The mean cost during the period of asleep DBS procedures was lower than that during the period of awake DBS procedures, but was not statistically significant. After adjusting for severity, varia-

TABLE 4. DBS UHC benchmark and OHSU costs*

\begin{tabular}{lrrrr}
\hline & \multicolumn{4}{c}{ Total Cost (\$) } \\
\cline { 2 - 5 } Variable & 2010 & 2011 & 2012 & 2013 \\
\hline 25th percentile & 20,569 & 22,614 & 25,129 & 23,755 \\
\hline Median & 26,921 & 29,153 & 33,335 & 34,052 \\
\hline 75th percentile & 34,692 & 43,725 & 43,411 & 44,930 \\
\hline 95th percentile & 61,775 & 66,051 & 67,613 & 56,643 \\
\hline OHSU cost & $\mathbf{1 8 , 6 8 0}$ & $\mathbf{2 3 , 2 6 8}$ & $\mathbf{1 9 , 5 1 5}$ & $\mathbf{1 7 , 1 5 0}$ \\
\hline Mean UHC volume $(\mathrm{n})$ & 20 & 36 & 37 & 42 \\
\hline Mean OHSU volume $(\mathbf{n})$ & $\mathbf{2 0}$ & $\mathbf{5 7}$ & $\mathbf{5 7}$ & $\mathbf{7 4}$ \\
\hline
\end{tabular}

${ }^{\text {* }}$ Costs are average costs per discharge. Data source: UHC Financial Database 2010-2013; 27 UHC principle members. 

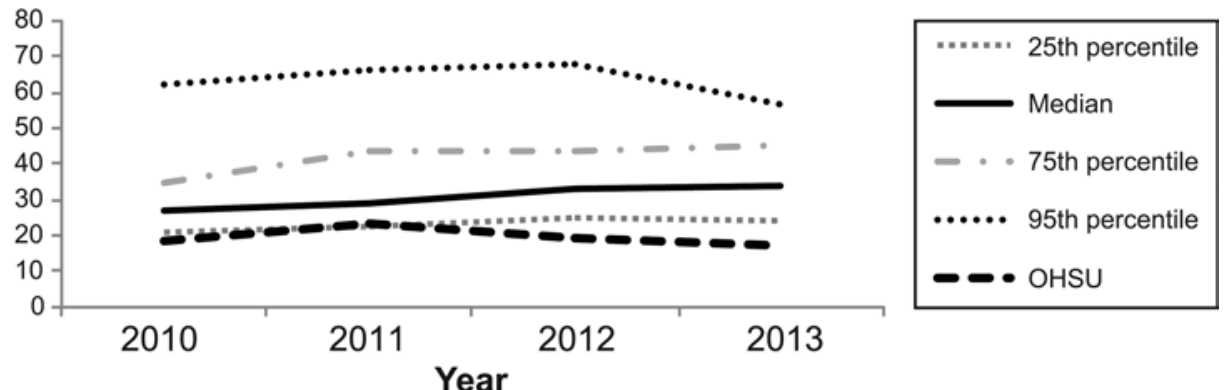

FIG. 2. Percentile average total cost per discharge for ICD-9 code 0293, using adult inpatient cost data from 27 UHC hospitals (2010-2013). Data source: UHC.

tion in cost was lower for asleep DBS when compared with awake DBS, and this difference was statistically significant (Table 3).

Costs by revenue category and DBS procedure were compared in Table 5. The column in the table labeled "Total Cost (\%)" indicates the percentage of total cost that is accounted for by the revenue category. After adjusting for severity of illness, the revenue categories indicated a significant difference in average costs by DBS procedure. For example, the per-patient costs of medical or surgical supplies were $\$ 26,515 \pm \$ 2914$ and $\$ 23,172 \pm \$ 3266$ for awake and asleep DBS procedures, respectively. Medical or surgical supplies account for $61.3 \%$ of the total cost of DBS procedures. Other revenue categories that were significantly lower for asleep DBS included anesthesia and MRI. Costs of OR services, recovery room, and CT increased with asleep DBS.

Total OR time for implantation of neurostimulator leads was calculated and upper and lower control limits were determined by data from the period prior to January 5, 2011, when awake DBS was performed at OHSU (Fig. 4). The mean OR times of awake DBS versus asleep DBS were compared, as indicated in Fig. 4 by the mean awake (Fig. 4, grey line) and mean asleep (Fig. 4, black line). One observation (1.8\%) is above the upper control limit in the awake period. Four observations (2.5\%) exceed 3 times the standard deviation in the asleep period. The mean OR time during the asleep period appears to be higher than that during the awake period (Table 3). However, in a severityadjusted model, this difference was not statistically sig- nificant. The difference in variance of OR time by awake versus asleep DBS, after adjusting for severity, remained not significant.

\section{Discussion}

There is a growing interest in the use of image guidance $^{18,21}$ as an alternative to microelectrode mapping ${ }^{15}$ for DBS electrode implantation. We have presented a detailed analysis of the costs of DBS implantation performed under general anesthesia with image guidance at OHSU. We have compared this result to a historical group of patients at OHSU who underwent DBS implantation under local anesthesia with microelectrode guidance. Costs included ICD-9 inpatient procedure code 0293 and outpatient costs closely associated with DBS, such as implantation of an IPG. The results show that there were no differences in readmissions, LOS, ICU LOS, OR time, and cost when these two types of procedures were compared within the same institution.

A more comprehensive understanding of costs associated with DBS requires outpatient and inpatient data. However, for the purposes of this study, obtaining outpatient data from other UHC institutions was not feasible. Despite this limitation, OHSU's cost for these procedures was lower than the median among comparable UHC institutions. We suggest that a comprehensive assessment of costs at high-volume UHC hospitals for these procedures would be interesting and add a higher level of confidence to future cost-effectiveness analyses. We are confident that

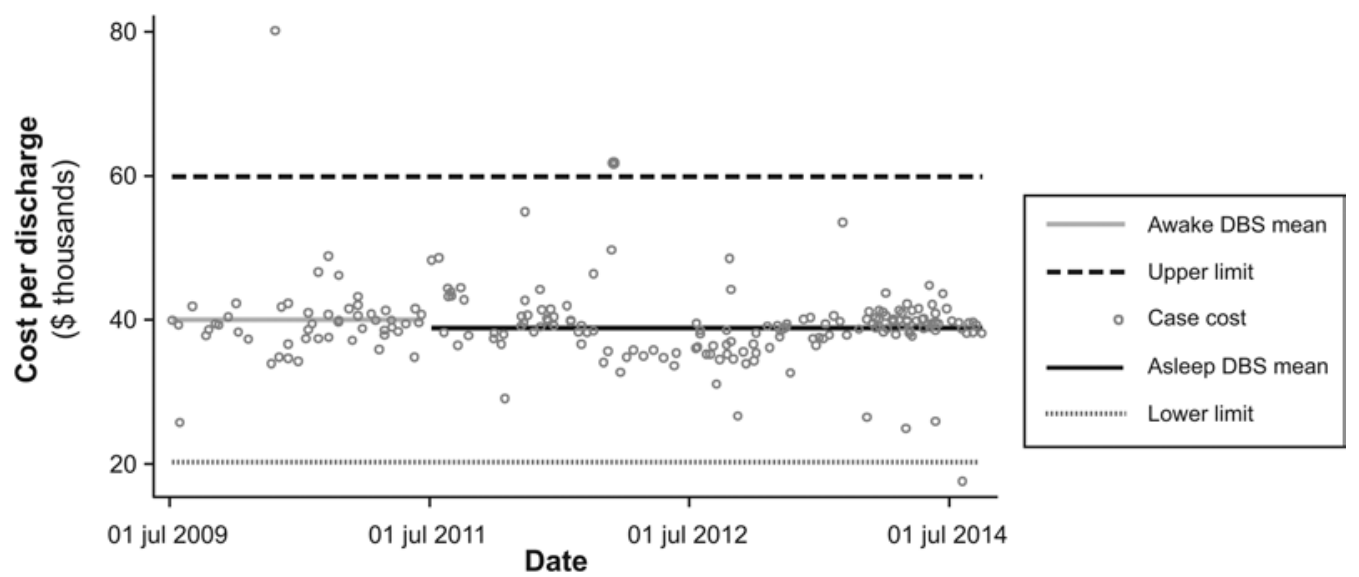

FIG. 3. Total OHSU DBS cost over time with upper and lower 3 standard deviations (July 2009-March 2014). Data source: OHSU. 
TABLE 5. OHSU DBS cost per patient by top revenue categories (July 2009-March 2014)

\begin{tabular}{|c|c|c|c|c|c|}
\hline Revenue Category & Mean Awake DBS Cost \pm SD (\$) & Mean Asleep DBS Cost \pm SD (\$) & Total Cost (\%) & Difference (\$) & $p$ Value \\
\hline Medical/surgical supplies & $26,515 \pm 2914$ & $23,172 \pm 3266$ & 61.3 & -3343 & $<0.001$ \\
\hline OR services & $6254 \pm 1576$ & $7660 \pm 1394$ & 18.7 & 1406 & $<0.001$ \\
\hline ICU & $2410 \pm 1293$ & $2612 \pm 1328$ & 6.5 & 202 & 0.582 \\
\hline Recovery room & $981 \pm 441$ & $1800 \pm 568$ & 4.1 & 819 & $<0.001$ \\
\hline Anesthesia & $702 \pm 175$ & $608 \pm 182$ & 1.6 & -94 & 0.001 \\
\hline Drugs requiring specific identification & $511 \pm 316$ & $555 \pm 277$ & 1.4 & 44 & 0.532 \\
\hline Room \& board (semiprivate, 2 beds) & $470 \pm 1806$ & $397 \pm 1523$ & 1.1 & -73 & 0.514 \\
\hline Coronary care & $214 \pm 673$ & $434 \pm 1058$ & 1 & 220 & 0.099 \\
\hline MRI & $602 \pm 172$ & $305 \pm 190$ & 1 & -297 & $<0.001$ \\
\hline Pharmacy & $304 \pm 144$ & $270 \pm 118$ & 0.7 & -34 & 0.116 \\
\hline CT & $30 \pm 92$ & $253 \pm 91$ & 0.5 & 223 & $<0.001$ \\
\hline Laboratory & $182 \pm 283$ & $195 \pm 246$ & 0.5 & 13 & 0.913 \\
\hline
\end{tabular}

cost analysis for DBS will become increasingly important as health care expenditures come under increasing pressure, and as these procedures are more in demand in an aging population.

This study may have limited generalizability, as it shows the experience of a single center; however, the performing surgeon at the center has set the standard for asleep DBS procedure methodology. Furthermore, the effects we show are the effects of the single surgeon performing first awake DBS, then asleep DBS. The differences we see in cost variation may be due to either secular trends or the change in practice from awake to asleep DBS. While we adjust for patient characteristics, it is possible that unmeasured factors may be causing the decrease in cost variation. Another potential bias for this study may include unobserved changes in practice style that could have occurred during the study period; however, this limitation may have been mitigated by the fact that the procedures were performed by the same physician. Practice patterns beyond the change from the awake to the asleep method are unlikely to have varied significantly.

One outcome of this study is that using the asleep DBS strategy, OR time and the cost variation of the procedure appear to be decreasing over time, presumably as the pro- cedure becomes more routine and predictable from the standpoint of imaging and intraoperative workflow. Of course, outcome is the most important aspect of any surgical innovation. The outcome in this particular analysis was cost. We are compiling our clinical outcome statistics, with long-term follow-up, in a subsequent report.

\section{Conclusions}

In this single academic medical center cost analysis, DBS performed while the patient was asleep was associated with a lower cost variation relative to the awake procedure. Furthermore, costs for asleep DBS compared favorably to those of high-volume UHC-affiliated institutions.

\section{Acknowledgments}

We thank Charles M. Kilo, MD, MPH, Oregon Health \& Science University, Chief Medical Officer, for administrative support.

\section{References}

1. Chambers A, Bowen JM: Electrical stimulation for drugresistant epilepsy: an evidence-based analysis. Ont Health Technol Assess Ser 13:1-37, 2013

2. Dams J, Bornschein B, Reese JP, Conrads-Frank A, Oertel

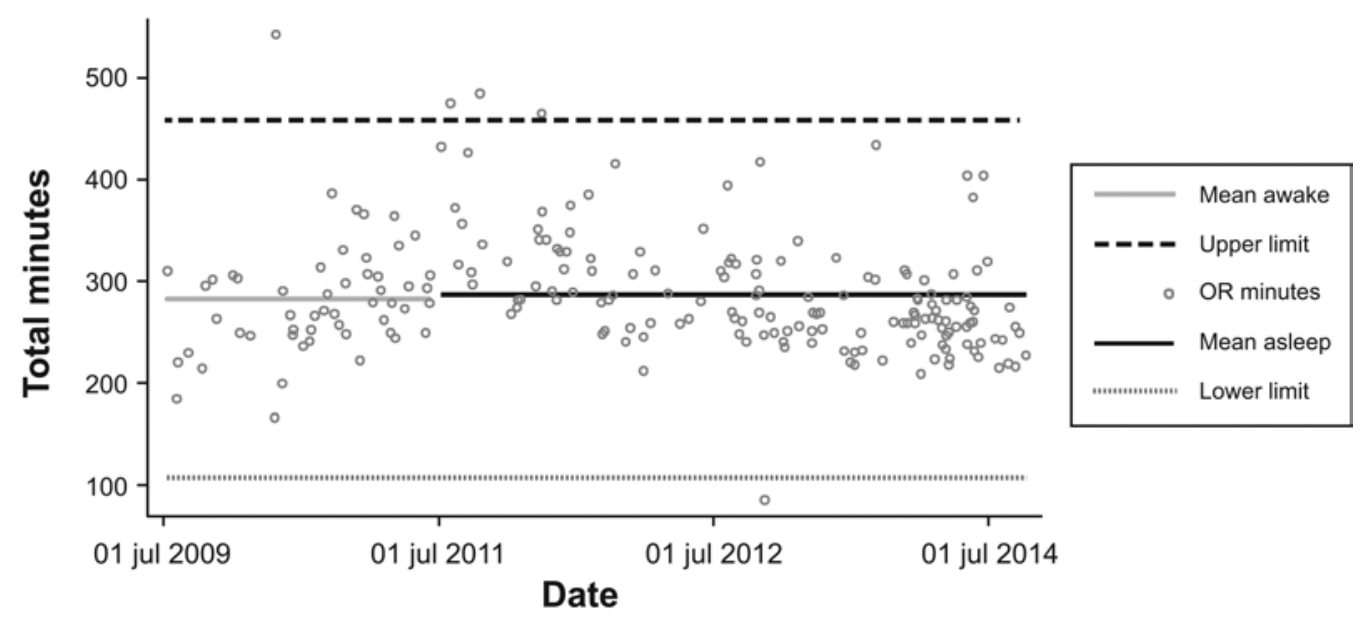

FIG. 4. OHSU OR minutes over time with upper and lower 3 standard deviations (July 2009-March 2014). Data source: OHSU. 
WH, Siebert U, et al: Modelling the cost effectiveness of treatments for Parkinson's disease: a methodological review. Pharmacoeconomics 29:1025-1049, 2011

3. Dams J, Siebert U, Bornschein B, Volkmann J, Deuschl G, Oertel WH, et al: Cost-effectiveness of deep brain stimulation in patients with Parkinson's disease. Mov Disord 28:763-771, 2013

4. Eggington S, Valldeoriola F, Chaudhuri KR, Ashkan K, Annoni E, Deuschl G: The cost-effectiveness of deep brain stimulation in combination with best medical therapy, versus best medical therapy alone, in advanced Parkinson's disease. J Neurol 261:106-116, 2014

5. Follett KA, Weaver FM, Stern M, Hur K, Harris CL, Luo P, et al: Pallidal versus subthalamic deep-brain stimulation for Parkinson's disease. N Engl J Med 362:2077-2091, 2010

6. Jürgens TP, May A: [Chronic cluster headache: how much does treatment cost?] Schmerz 24:221-225, 2010 (Ger)

7. Leone M, Franzini A, Cecchini AP, Mea E, Broggi G, Bussone G: Costs of hypothalamic stimulation in chronic drugresistant cluster headache: preliminary data. Neurol Sci 30 (Suppl 1):S43-S47, 2009

8. McClelland S III: A cost analysis of intraoperative microelectrode recording during subthalamic stimulation for Parkinson's disease. Mov Disord 26:1422-1427, 2011

9. McIntosh E, Gray A, Aziz T: Estimating the costs of surgical innovations: the case for subthalamic nucleus stimulation in the treatment of advanced Parkinson's disease. Mov Disord 18:993-999, 2003

10. McIntosh ES: Perspective on the economic evaluation of deep brain stimulation. Front Integr Nuerosci 5:19, 2011

11. Meissner W, Schreiter D, Volkmann J, Trottenberg T, Schneider GH, Sturm V, et al: Deep brain stimulation in late stage Parkinson's disease: a retrospective cost analysis in Germany. J Neurol 252:218-223, 2005

12. Ng WH, Thomas J: A simple and cost-effective method of fixation of deep brain stimulation (DBS) electrode. Acta Neurochir (Wien) 150:387-389, 2008

13. Sampietro-Colom L, Morilla-Bachs I, Gutierrez-Moreno S, Gallo P: Development and test of a decision support tool for hospital health technology assessment. Int J Technol Assess Health Care 28:460-465, 2012

14. Spottke EA, Volkmann J, Lorenz D, Krack P, Smala AM, Sturm V, et al: Evaluation of healthcare utilization and health status of patients with Parkinson's disease treated with deep brain stimulation of the subthalamic nucleus. J Neurol 249:759-766, 2002

15. Sterio D, Zonenshayn M, Mogilner AY, Rezai AR, Kiprovski
K, Kelly PJ, et al: Neurophysiological refinement of subthalamic nucleus targeting. Neurosurgery 50:58-69, 2002

16. Stroupe KT, Weaver FM, Cao L, Ippolito D, Barton BR, Burnett-Zeigler IE, et al: Cost of deep brain stimulation for the treatment of Parkinson's disease by surgical stimulation sites. Mov Disord 29:1666-1674, 2014

17. Tomaszewski KJ, Holloway RG: Deep brain stimulation in the treatment of Parkinson's disease: a cost-effectiveness analysis. Neurology 57:663-671, 2001

18. Vega RA, Holloway KL, Larson PS: Image-guided deep brain stimulation. Neurosurg Clin N Am 25:159-172, 2014

19. Weaver FM, Follett K, Stern M, Hur K, Harris C, Marks WJ $\mathrm{Jr}$, et al: Bilateral deep brain stimulation vs best medical therapy for patients with advanced Parkinson disease: a randomized controlled trial. JAMA 301:63-73, 2009

20. Zhu XL, Chan DT, Lau CK, Poon WS, Mok VC, Chan AY, et al: Cost-effectiveness of subthalamic nucleus deep brain stimulation for treatment of advanced Parkinson's disease in Hong Kong: a prospective study. World Neurosurg 82:987993, 2014

21. Zrinzo L, Foltynie T, Limousin P, Hariz M: Image-verified deep brain stimulation reduces risk and cost with no apparent impact on efficacy. Mov Disord 27:1585-1587, 2012

\section{Disclosures}

Dr. Burchiel is Founder and President of CereMod, Inc., a medical device company.

\section{Author Contributions}

Conception and design: Burchiel. Acquisition of data: Burchiel, Jacob, Geddes. Analysis and interpretation of data: Burchiel, Jacob, Geddes. Drafting the article: all authors. Critically revising the article: all authors. Reviewed submitted version of manuscript: all authors. Approved the final version of the manuscript on behalf of all authors: Burchiel. Statistical analysis: Jacob, Geddes. Administrative/technical/material support: Burchiel, McCartney. Study supervision: Burchiel.

\section{Correspondence}

Kim J. Burchiel, Department of Neurological Surgery, Oregon Health \& Science University, 3303 SW Bond Ave., Mail Code CH8N, Portland, OR 97239. email: burchiek@ohsu.edu. 